Revista de Comunicación y Salud, 2020, Vol. 10, no 2, pp. 25-61

Editado por Cátedra de Comunicación y Salud

ISSN: 2173-1675

\title{
COVID-19: CONTENIDOS AUDIOVISUALES A PARTIR DEL USO DE HERRAMIENTAS DOMÉSTICAS
}

\section{COVID-19: audiovisual content from the use of household tools}

\author{
Julio Blas Blas ${ }^{1}$ \\ Universidad Complutense de Madrid. España. \\ julioblas@ucm.es \\ Alberto Luis García García \\ Universidad Complutense de Madrid. España. \\ algarci@ucm.es \\ Ignacio José Martín Moraleda \\ Universidad Complutense de Madrid. España. \\ ignmar05@ucm.es
}

\section{Resumen}

La aparición del virus COVID-19 supuso el confinamiento de personas y el cese de actividades. En la industria audiovisual ha supuesto cambios en la producción de contenidos, como, por ejemplo, el uso de videollamadas como técnica de producción. Metodología: se ha empleado una metodología de tipo cualitativo mediante entrevistas en profundidad a expertos para conocer su análisis de la situación y su desarrollo. Además, con la revisión bibliográfica se establecen las bases sobre los que se han articulado los cambios. Resultados: El estudio describe un escenario adaptativo de la industria para seguir produciendo con la implementación de novedosos flujos de trabajo. Discusión: los resultados se han analizado bajo la perspectiva de un modelo de análisis DAFO que permite articular de manera sencilla las consecuencias del nuevo escenario en el audiovisual y su influencia en el futuro. Conclusiones: el artículo se centra en las principales áreas de cambio del audiovisual causados por el COVID: estética, flujos de trabajo y sostenibilidad.

Palabras clave: teletrabajo; televisión; producción; nuevas herramientas; sostenibilidad; COVID-19.

\footnotetext{
1 Autor para correspondencia: Julio Blas Blas'1. julioblas@ucm.es. Profesor Asociado Universidad Complutense de Madrid.
} 
COVID-19: contenidos audiovisuales a partir del uso de herramientas domésticas

\begin{abstract}
The appearance of the Covid-19 virus meant the confinement of people and the cessation of activities. In the audiovisual industry it has meant changes in the production of content, such as the use of video calls as a production technique. Methodology: a qualitative methodology has been used through in-depth interviews with experts to learn about their analysis of the situation and its development. In addition, with the bibliographic review, the bases on which the changes have been articulated are established. Results: The study describes an adaptive scenario of the industry to continue producing with the implementation of new workflows. Discussion: The results have been analyzed under the perspective of a SWOT analysis model that allows to articulate in a simple way the consequences of the new scenario in the audiovisual industry and its influence in the future. Conclusions: the article focuses on the main areas of change in the audiovisual caused by the COVID: aesthetics, workflows and sustainability.
\end{abstract}

Keywords: teleworking; television; production; new tools; sustainability; COVID-19.

\title{
Cómo citar el artículo
}

Blas Blas, J., García García, A. L. y Martín Moraleda, I. J. (2020). COVID-19: contenidos audiovisuales a partir del uso de herramientas domésticas. Revista de Comunicación y Salud, 10 (2), 25-61.

doi: https://doi.org/10.35669/rcys.2020.10(2).25-61

\section{INTRODUCCIÓN}

Las crisis azotan todos los sectores productivos y el audiovisual, en concreto, suele ser de los más damnificados. En épocas donde la economía se tambalea, cada industria se adapta y modifica a las necesidades y retos que se le plantean.

Ya en 2011 y 2012 el Análisis Televisivo Anual (Barlovento, 2009-2013 en Francés, 2014, p. 146) reflejaba que, dada la situación de crisis económica mundial, el mercado de la producción audiovisual atravesaba un mal momento económico a consecuencia de la crisis de la financiación publicitaria y, más importante, no se veían esperanzas de crecimiento a corto plazo. Se encargaban menos producciones y más baratas.

Las épocas de crisis suponen un cambio y una adaptación de la industria a las nuevas circunstancias. En tanto que las situaciones económicas se complican, el empleo se resiente, desembocando en una precarización laboral en todos los perfiles profesionales ya que recorren la cadena de valor de la industria audiovisual (Francés, 2014).

También señala Francés (2014) que los medios de comunicación de masas han tenido una presencia y papel relevante en cada acontecimiento histórico sucedido desde su nacimiento a mediados del siglo XX. De manera que la primera pandemia del 
COVID-19: contenidos audiovisuales a partir del uso de herramientas domésticas

siglo XXI ha formado parte activa de los medios $y$, en consecuencia, hay que saber en qué los ha afectado.

El desarrollo tecnológico y de distintas aplicaciones informáticas también se ha ido implementando progresivamente en las producciones audiovisuales (Clemente, 2004). Pero lo que ha jugado un papel fundamental en la forma de trabajar y de producir en televisión ha sido el uso creciente de las redes de comunicación a través de Internet.

Durante el confinamiento, las videollamadas han acaparado las pantallas, lo que indica el acierto de la tendencia reflejada por Menéndez-Manjón (2003) sobre que, la mejora en las comunicaciones digitales y el flujo de datos impulsa la producción y distribución de contenidos.

Lo que se viene observando desde hace años es que ya no se necesita salir de la redacción para conocer lo que pasa en el mundo, (Heredero y Reyes, 2016) y que, en las actuales condiciones de trabajo de los profesionales de la comunicación, sometidos a la ley del «hágaselo usted mismo» (DIY-Do It Yourself, en inglés), hay que producir, redactar, grabar y editar sus piezas. Esto es una consecuencia más de la integración de la tecnología en el flujo del trabajo, que no sólo hace del profesional de los medios un sujeto multitarea, sino que le impone la dificultad de competir con todos aquellos que disponen en sus casas de la misma tecnología.

Uno de los efectos más relevantes de la crisis económica de 2008 en el sector audiovisual tuvo que ver con la sustitución total de la tecnología analógica por la digital. Este hecho supuso un abaratamiento de los costes de procedimientos y herramientas, aupadas, además, por el auge de plataformas como Youtube (Heredero y Reyes, 2016) que permitieron mayor alcance en la distribución de contenidos.

Durante años, para crear cualquier producto audiovisual -una simple rueda de prensa, por ejemplo- se necesitaban una cantidad numerosa de recursos técnicos y humanos (Casanova, 2016). La evolución hacia tecnologías digitales de producción cuenta con ejemplos de producción de bajo presupuesto como el videoclip Lost Ones, de la artista Joan Thiele, dirigido y producido por Giada Bossi para la discográfica Universal, en el que el presupuesto completo -incluyendo todas las fases- fue de 5.000 euros, utilizando una cámara tipo réflex con capacidad de rodar en 4K (Pérez-Rufí, 2018, p. 297).

Los efectos de la crisis también supusieron la democratización de la producción: al ser más económico el acceso a la tecnología audiovisual para producir, aparecen nuevos formatos como las webseries, en las que las empresas encuentran una nueva ventana publicitaria influida por las redes sociales. (Segarra et al., 2017). Y es que "los videoclips se han posicionado como uno de los formatos centrales de la renovación del audiovisual por su capacidad de adaptación a los canales de distribución digitales y de hibridación con otros formatos" (Sedeño et al., 2016).

Revista de Comunicación y Salud, 2020, Vol. 10, nº 2, pp. 25-61 
COVID-19: contenidos audiovisuales a partir del uso de herramientas domésticas

El COVID requiere investigaciones de la televisión que analicen su papel en la comunicación y sus efectos, como indican Hermes y Hill (2020) donde apuntan a que la televisión ofrece una seguridad ontológica y deshace la distancia social.

La crisis financiera de 2008, además, supuso el nacimiento de la figura de trabajador multitarea. La aparición de tecnología más económica y la pérdida del requisito de calidad técnica en determinados productos trajo consigo, como hemos visto, estrategias de producción basadas en el low cost en el que se ha primado la cantidad sobre la calidad. Este nuevo paradigma conocido como la democratización de los medios digitales, trajo consigo una reducción importante de los recursos humanos, la ausencia de estabilidad laboral y de las producciones bien remuneradas, una consecuencia que continúa hoy (Casanova, 2016).

Otro factor fundamental, consecuencia del desarrollo tecnológico, fue la aparición de los teléfonos móviles inteligentes. En los albores ya se vislumbraba su uso como plataforma de distribución y consumo de contenidos, llegándose a formular distintas propuestas específicas de adaptación a su formato pequeño y portátil y, también, al visionado en condiciones de escaso tiempo y en cualquier lugar, fuera de la comodidad controlada del hogar o las salas de cine (Vinader et al., 2010).

En un sólo dispositivo disponemos de una cámara de alta resolución, programas de edición y postproducción de audio y vídeo y la posibilidad de la transmisión de datos. Esa característica ha sido, en este momento, de vital importancia para poder mantener las comunicaciones con la intención de emitir contenidos televisivos. Hasta hace muy poco tiempo, se pasó de necesitar complejos sistemas de comunicación; como las antenas de transmisión satelital terrenal (DSNG), a dispositivos más sencillos; como las mochilas 4G, que aun así necesitaban la contratación de determinados servicios.

En este momento eso ha desaparecido. Sólo basta el terminal móvil. Es la smartphonograpy, que se define como:

La tendencia a capturar lo cotidiano, lo que nos acompaña en nuestro día a día, el paisaje urbano, representar las escenas de nuestro alrededor desde la mirada más creativa, con retoques personalizados a través de múltiples aplicaciones para finalmente divulgar y publicar su contenido. (Casanova, 2016)

Esta tendencia ha saltado, directamente, del ámbito doméstico al profesional. Aunque lo que puede tener consecuencias negativas a la hora de determinadas relaciones laborales y de calidad, también tiene consecuencias positivas como destapar talento creativo que antes, sin poder acceder a las herramientas profesionales, eran difíciles de descubrir y de gestionar.

Pero una de las variables que más se han trastocado en la crisis del 2020 respecto a la crisis del 2008, ha sido la variable medioambiental. Por una parte, ha aumentado el número de deshechos de plástico por el incremento del consumo de productos envasados y el uso de mascarillas y deshechos de tipo sanitario (Cepeda, 2020). A escala industrial, la parada en la actividad ha supuesto un descenso en la emisión de

Revista de Comunicación y Salud, 2020, Vol. 10, no 2, pp. 25-61 
COVID-19: contenidos audiovisuales a partir del uso de herramientas domésticas

gases contaminantes a la atmósfera. Los recursos son finitos y desde mediados de los años 70 del siglo XX ya se advertía con preocupación del legado que se dejaría a generaciones futuras. (Gómez, 2020). La interacción de la actividad humana con el entorno tiene que mantener un delicado equilibrio:

Se ha confirmado que los problemas sanitarios están siempre sujetos a la interacción de cada civilización con su entorno, lo que depende, en esencia, del carácter de la relación hombre-naturaleza. (Gómez, 2020)

De manera que hay una relación directa entre la industria y el entorno. Gómez, (2020) afirma que "hay que aprender a gestionar responsablemente los desechos que se generan, porque lo que se haga hoy tendrá implicaciones en el futuro y lo que se haga en un lugar del planeta repercutirá en otro, pues este mundo es un todo único, continuo y tridimensional".

En cuanto a la actividad empresarial, López y Bulmer (2020) señalan que:

A nivel empresarial, la sostenibilidad tiene que existir desde el core del negocio y estar presente de manera transversal en toda la organización. Y si de sostenibilidad se trata, es preciso centrarse, desde el inicio, en el cumplimiento de los 17 Objetivos de Desarrollo Sostenible. (López y Bulmer, 2020)

Dicho lo cual, resulta crucial plantear nuevos flujos de trabajo en las producciones audiovisuales que tengan en cuenta el factor ambiental, al mismo tiempo que los recursos tecnológicos, la capacidad de distribución global y la gestión virtual de los recursos humanos.

La crisis actual ha conllevado una doble consecuencia: la sanitaria, obligando a las personas a confinarse en lugares cerrados lo que ha modificado, entre otros aspectos, el espacio de interacción con el contenido audiovisual y, por otra parte, una crisis financiera motivada por el parón económico que ha supuesto. Si cualquier época de crisis implica una reinvención, adaptación, resiliencia y aprendizaje de lecciones aprendidas anteriores, surgen las siguientes cuestiones:

¿Cómo se han adaptado los procesos productivos y de realización a las circunstancias de movilidad cero? Ante esa movilidad cero, ¿ha influido en cuestiones de sostenibilidad?. Además, dado que los empleados debían quedarse en sus domicilios, ¿qué impacto ha tenido en la gestión de recursos humanos?.

\section{OBJETIVOS}

El objeto de la presente investigación es conocer la manera en que la industria audiovisual ha continuado con su actividad durante el confinamiento, motivado por el COVID-19 y de qué manera ha influenciado en dichas empresas para poder proponer modos de gestión y flujos de trabajo aplicables en un futuro próximo en el sector audiovisual. 
COVID-19: contenidos audiovisuales a partir del uso de herramientas domésticas

Es, por tanto, fundamental establecer 0 , al menos, reflexionar sobre las posibilidades , dentro de un escenario real, en el que se integre las importantes necesidades técnicas para producir televisión, con la correcta formación sobre el uso de dichas herramientas. El objetivo es establecer flujos de trabajo fiables con capacidad de crear un producto de calidad en la línea que van a exigir los espectadores.

El escenario que ha traído consigo el teletrabajo, también ha generado nuevas oportunidades de empleo condicionadas por las posibilidades técnicas y operativas utilizadas en los procesos televisivos.

Y en relación con el medio ambiente, el objetivo general es el estudio de la implementación de prácticas sostenibles en la producción como variable fundamental para entender el futuro de la economía.

Para ello, es necesario plantear la investigación bajo dos perspectivas:

- La primera tiene que ver con el punto de vista académico ya que, aunque una crisis como la planteada por el COVID-19 no había ocurrido previamente, sí existen trabajos de investigación en relación con la producción low cost y fórmulas novedosas de realización audiovisual que implican economía en los medios de producción.

- La segunda, debe tener en cuenta la experiencia profesional directa. La producción audiovisual y, en concreto la televisión, ha sufrido un aumento de audiencias extraordinario durante la pandemia. Del 16 de marzo al 21 de junio el consumo televisivo aumentó un $22 \%$ más que en el mismo periodo del pasado año, 278 minutos por persona y día (Barlovento Comunicación, 2020, p. 4). Y como consecuencia de ello, los programas más vistos han tenido que adaptar sus estrategias de producción de manera obligatoria para ajustarse a la normativa estatal.

Hay que tener en cuenta que la situación que se está viviendo por el COVID-19 es tan excepcional que, con toda probabilidad, será difícil que se repita en las mismas circunstancias.

Por lo tanto, los objetivos específicos que trataremos de alcanzar son:

- Establecer cuáles de los trabajos de investigación y los resultados conseguidos para fórmulas de producción de bajo coste, pueden ayudar a explicar las posibilidades que han aparecido con el teletrabajo explicada como una realidad asumida por empresas y trabajadores.

- En ese entorno, se investigará la solución a los problemas surgidos por la situación de reducción de la movilidad, así como las soluciones y mejoras aportadas.

- Explicar y dar a conocer las técnicas de producción y realización televisiva que se han desarrollado durante la pandemia. Este objetivo tiene su validez en tanto y cuanto que son los mismos profesionales que han llevado a cabo esta transformación, los que explican este hecho.

Revista de Comunicación y Salud, 2020, Vol. 10, nº 2, pp. 25-61 
COVID-19: contenidos audiovisuales a partir del uso de herramientas domésticas

- Además, se abordarán las posibilidades derivadas del trabajo en remoto y, más concretamente, en el área de la televisión, atendiendo a criterios estéticos, de flujo de trabajo. Se trata de aliviar las necesidades de producción en un sector tan crítico, desde el punto de vista económico, como es el audiovisual.

- En cuanto al aspecto medioambiental, el objetivo es investigar las medidas aplicadas por las empresas en cuestiones de sostenibilidad y si están presentes en los planes de ejecución de los proyectos.

\section{METODOLOGÍA}

Se han seguido dos métodos de investigación principal. Por un lado, la revisión bibliográfica y reseñas en páginas especializadas audiovisuales y prensa de ámbito nacional. Por el otro, una serie de entrevistas cualitativas no estructuradas (tabla 1) a realizadores; jefes técnicos y productores de distintas cadenas de televisión y productoras audiovisuales de España (tabla 2), con la suficiente experiencia y cualificación profesional como para ser considerados como expertos en la materia.

Tabla 1. Preguntas de las entrevistas realizadas a profesionales.

1. ¿Qué tecnología han implementado las cadenas para establecer las comunicaciones? ¿Qué software han utilizado y cómo han gestionado las comunicaciones?

2. ¿Cómo han resuelto los problemas de monitoreado y envío de señales de órdenes?

3. ¿Qué impacto ha supuesto en los procesos de realización en control? ¿Ha habido cambios sustanciales?

4. ¿Las técnicas y contenidos utilizados estos meses pasarán a ser consideradas una herramienta más para la producción de contenidos?

5. ¿Qué impacto ha tenido sobre el personal y recursos humanos?

6. ¿Puede haber una reorganización de los recursos humanos y del teletrabajo en la producción de contenidos?

7. Desde el punto de vista de los contenidos, las empresas audiovisuales se han adaptado a los cambios ¿Son formas de narrar que pasarán a ser una herramienta más para el desarrollo de contenidos? ¿O son un recurso temporal motivado por la situación?

8. ¿Se han implementado protocolos de actuación por si vuelven a ocurrir circunstancias similares?

9. ¿Ha tenido algún impacto sobre la sostenibilidad, reducción de residuos, gastos de transporte, vehículos o iluminación?

10. ¿Los nuevos procesos y las lecciones aprendidas vienen para quedarse o ha sido una experiencia temporal que no volverá a usarse?

Fuente: Elaboración propia.

Las entrevistas se han realizado mediante conversación telefónica, que posteriormente han sido transcritas y de ellas se ha extraído la información.

Dada la cantidad de formatos que existen en el ámbito audiovisual (informativos, ficción, realities, docudrama o concursos, etc.) se ha decidido efectuar un mapa de elementos comunes empleados en diferentes formatos, atendiendo más a los 
COVID-19: contenidos audiovisuales a partir del uso de herramientas domésticas

procedimientos que al propósito final. La intención es establecer un marco general de uso en distintos programas, sin querer limitar la investigación a un único producto.

Además, se han revisado artículos de prensa en los que se han publicado soluciones y adaptaciones que se han producido en esta situación. La novedad en el objeto de la investigación hace que no haya apenas referencias de investigaciones anteriores.

Para acabar con la triangulación en la investigación metodológica, se analizarán los resultados de los datos obtenidos en la investigación a través de un análisis que mantiene la estructura metodológica del método DAFO, pero que no ha contado -por cuestiones obvias- con una segunda oleada de análisis.

El objetivo de aplicar esta metodología es sentar las bases sobre las que articular premisas para la construcción de un posible escenario de producción virtual, basado en la experiencia de aquellos profesionales que han tenido que tomar las decisiones ejecutivas durante la pandemia para adaptar, casi instantáneamente, los flujos de trabajo a las necesidades de producción impuestas por la crisis sanitaria.

Tabla 2. Entrevistados, empresa y perfil profesional.

\begin{tabular}{lll}
\hline \multicolumn{1}{c}{ Nombre } & \multicolumn{1}{c}{ Empresa } & \multicolumn{1}{c}{ Perfil profesional } \\
\hline Jorge Alonso & Mediaset España & Jefe de Realización de Informativos \\
Federico Atienza & Mediaset España & Jefe de Producción de Informativos \\
Vicente Peña & Cuarzo & Jefe de Realización \\
Emili Planas & Mediapro & Chief Technical Officer (CTO) \\
Víctor Santamaría & Movistar+ & Jefe de Realización de Deportes \\
Javier Torrijos & Telefónica Broadcast Services (TBS) & Supervisor de Branded Content \\
Álvaro Santamarina & Atresmedia & Realizador \\
José Jiménez & Andalucía Digital Multimedia & Realizador \\
Pedro Martín Ortega & Telefónica Broadcast Services (TBS) & Jefe Unidades Móviles \\
\hline
\end{tabular}

Fuente: Elaboración propia.

\section{ANÁLISIS Y RESULTADOS}

En enero de 2020 surgen las primeras noticias de un "misterioso coronavirus surgido en China", (ABC, 2020). El 31 de enero la OMS declara la emergencia sanitaria (Güell, 2020). En España, el 13 de marzo de 2020 se decreta el Estado de Alarma que obligaba a la población a confinarse en sus domicilios. 
COVID-19: contenidos audiovisuales a partir del uso de herramientas domésticas

La consecuencia principal es el parón en seco de la producción, también del sector audiovisual, que se vio abocado a modificar sus estructuras de personal, formas de producción y realización de contenidos.

En las diferentes parrillas de programación se dejan de emitir programas en directo y la producción de programas en diferido se frena de manera drástica ante la imposibilidad de realizar grabaciones en plató. La adaptación ante esta nueva circunstancia se antoja inminente convirtiendo el mantenimiento de la capacidad de emisión en el caso de que el coronavirus aparezca entre su personal técnico como la mayor preocupación de los ejecutivos de las cadenas de televisión (Así golpea el coronavirus las cadenas de televisión, 2020), por lo que reinventar nuevos flujos de trabajo es fundamental.

Pero al mismo tiempo, la creatividad permite crear programas de televisión realizados desde las casas particulares: presentadores, colaboradores, invitados, etc., que aparecen frente a las cámaras - con sus librerías a la espalda - a través de sus dispositivos electrónicos, móviles y ordenadores. El Intermedio o Zapeando (Mediapro Studios, 2020) se producen con todo el personal artístico en sus casas. El Hormiguero (Siete y Acción, 2020) por su parte opta por un formato híbrido con parte del personal en plató y otros en sus hogares. Las gradas del público se comienzan a vaciar. Primero al cincuenta por ciento del aforo. Luego vacío por completo (Así golpea el coronavirus las cadenas de televisión, 2020)

Por otra parte, los contenidos también se ven afectados en tanto en cuanto surgen nuevos formatos y programas creados de forma específica para la situación, realizados con tecnologías móviles y con guiones centrados en la pandemia (Pérez, 2020) como Diarios de la cuarentena para TVE (RTVE, Morena Films, 2020), o la productora El Terrat que lanza su webserie Coronavídeos: historias confinadas (El Terrat, 2020).

Además, todos los sectores dentro de la industria audiovisual se ponen en marcha para adaptarse a la situación y seguir produciendo en la medida de lo posible. Muestra de ello es el sector del doblaje cinematográfico, que implementa un flujo de trabajo para que los actores dispongan en su domicilio de un micrófono profesional tipo Newman conectado a un ordenador que, de forma remota, se vincula al sistema de sonido y visionado de takes (fragmentos de secuencias en las que se divide el producto audiovisual a la hora del trabajo de doblaje), para poder sincronizar y grabar las tomas (Abel, 2020).

Por su parte, la empresa de alquiler de material audiovisual Ovide (Realización remota, producción y streaming profesional para productoras, s.f.), ofrece un servicio para realización virtual en remoto donde cada trabajador puede estar en su casa.

En definitiva, el obligado parón productivo y la consecuente necesidad de reinvención, ha reflejado modificaciones positivas en distintos sectores:

Revista de Comunicación y Salud, 2020, Vol. 10, nº 2, pp. 25-61 
COVID-19: contenidos audiovisuales a partir del uso de herramientas domésticas

La irrupción del coronavirus también ha dejado huellas positivas, como la heroica labor de múltiples profesionales, la solidaridad de las sociedades, el respiro medioambiental o el impulso que ha dado al teletrabajo y a la Cuarta Revolución Industrial y sus tecnologías, a las que no es ajena la prensa en cualquiera de sus formatos. (Corral, 2020)

Vemos que la situación ha producido cambios en diferentes elementos del proceso de producción. Por una parte, la realización de programas ha salido de plató y, resulta fundamental, plantearse la eficacia de las soluciones a los flujos de trabajo que, a escala técnica, se han adoptado para la realización de programas.

El propio espacio físico se ha modificado y el personal que tiene que desplazarse a los controles, se encuentran con un elemento nuevo para prevenir posibles contagios; como las mamparas de separación entre puestos (Custom Consoles estrena una mampara para controles de realización como respuesta al COVID-19, s.f.). Los platós se vacían o conviven con los domicilios. Es necesario integrar esa comunicación entre los centros de producción y las herramientas disponibles en los hogares o aquellas que se pueden introducir en los hogares de los trabajadores para crear flujos de trabajo totalmente nuevos. $Y$ si muchas personas se han quedado en sus domicilios sin desplazarse físicamente a los centros de producción, ¿cómo ha afectado a la manera de trabajar?.

En otro orden de cosas, la gestión de la producción también se ve afectada al tener que modificar las necesidades de localización y transporte. El propio confinamiento ha supuesto un descenso en cuestiones de emisión de gases tóxicos a la atmósfera. Tanto es así que los niveles de NO2 registrados durante el estado de alarma son los más bajos para la segunda quincena de marzo y el mes de abril de la última década (Ceballos et al., 2020, p. 11).

En cuanto a la generación de residuos, objetivos como la reducción de plásticos han supuesto un retroceso en los hitos logrados hasta el momento. El motivo ha sido el aumento de envases alimenticios o los desechos sanitarios como mascarillas (Cepeda, 2020).

El impacto tanto de las emisiones de $\mathrm{CO} 2$ como del aumento de la temperatura media del planeta, muestran la insostenibilidad ambiental y la urgencia de encontrar soluciones para paliar sus efectos (López y Bulmer, 2020). Surge la pregunta de si las empresas productoras tienen en cuenta factores de sostenibilidad para su industria.

Tras observar las publicaciones en prensa, informes de instituciones y la observación de programas de televisión se ha procedido a la búsqueda de información específica académica acerca del tema.

En primer lugar, se ha decidido elegir en base al tema, las dos palabras más generales: audiovisual y COVID y efectuamos la búsqueda limitada al año 2020.

Revista de Comunicación y Salud, 2020, Vol. 10, no 2, pp. 25-61 
COVID-19: contenidos audiovisuales a partir del uso de herramientas domésticas

Los resultados que arroja Scopus son veinte, todos relacionados con la telemedicina, la realidad virtual en aplicaciones médicas, cirugía, radiología. En definitiva, no devuelve ningún tema de interés para nuestro estudio.

Efectuamos la misma búsqueda en Web Of Science que nos ofrece los mismos resultados que Scopus, pero añade un artículo de Giulio Latini (Latini, 2020) que versa sobre el análisis textual de la imagen y la comunicación, tomando como base cuestiones epistemológicas y de lenguaje, de manera que se aleja de nuestro objeto de estudio.

A continuación, procedemos a ejecutar la misma búsqueda en Dialnet que arroja para el año 2020 un total de siete resultados y ninguno del objeto de nuestro estudio.

Por último, Google Scholar nos ofrece 3.550 resultados. Revisados los primeros, la búsqueda devuelve artículos médicos, pero hemos encontrado uno que repasa la comunicación audiovisual general durante la pandemia y analiza los contenidos, desde programas de televisión como El Hormiguero hasta redes sociales como Instagram (Pérez-Rufí, 2020)

A continuación, efectuamos un cambio en la búsqueda. Sustituimos audiovisual por televisión y mantenemos COVID y la limitación temporal a 2020.

La base de datos Scopus arroja 63 artículos, del entorno sanitario en su mayor parte, pero devuelve dos que se acercan a nuestro propósito. Uno de ellos describe de manera superficial el entorno y las formas de comunicarse durante los tiempos de pandemia (Hermes y Hill, 2020).

Por otro lado, encontramos otro documento que versa sobre herramientas de comunicación a través de internet pero no hemos podido tener acceso (Suciu et al., 2020).

La búsqueda en Web Of Science nos ofrece un total de 38 resultados para las palabras televisión y Covid en 2020, de los cuales encontramos uno sobre el tratamiento de los mensajes y la información (Casero-Ripollés, 2020). También se extrae otro artículo con una reflexión acerca de la influencia general en los contenidos, pero sin la intención o profundidad de nuestra investigación (Ong y Negra, 2020)

Por su parte, Dialnet, una vez hecha la misma búsqueda, no ofrece ningún resultado para el año 2020.

Finalmente, realizamos la búsqueda en Google Scholar. Nos ofrece 6.360 resultados para el año 2020. Entre los 50 primeros resultados, ninguno es de nuestro interés dado que se centran en temas médicos. Sí encontramos algunas de las referencias anteriores devueltas en otros buscadores. 
COVID-19: contenidos audiovisuales a partir del uso de herramientas domésticas

De manera que, hecha la búsqueda en los cuatro principales motores de artículos académicos sin tener información relevante, hemos realizado entrevistas para obtener datos cuantitativos sobre la repercusión de la crisis sanitaria en las formas de producción televisiva.

\subsection{Comunicaciones}

Las comunicaciones durante la pandemia se han tenido que adaptar de manera rápida para poder dar servicio a la producción de programas.

En cuanto a cuestiones relativas a las señales involucradas para la realización audiovisual, Vicente Peña, jefe de realización de la productora Cuarzo (Peña, V., comunicación personal, 13 de mayo de 2020) indica que, se establecen mediante sistemas de videollamada tipo Zoom o a través del sistema integrado de realización virtual LiveStream Studio.

Las comunicaciones y órdenes técnicas con las personas que están fuera, dependen del sistema utilizado. En el caso de LiveStream Studio, al ser un sistema estándar de realización; aunque virtual, envía en primer lugar una invitación, que, al ser aceptada, pasa a ser integrada dentro del sistema de realización remota y, por tanto, se efectúan los envíos y retornos como se haría desde cualquier control (Peña, 2020).

Por su parte, Víctor Santamaría, Jefe de Realización de Deportes de Movistar+ (Santamaría, V., comunicación personal, 1 de junio de 2020) añade el uso de sistemas de mensajería y videollamada como Skype, Zoom o Microsoft Teams además de la aplicación DMNG App de Aviwest, que es una empresa proveedora de los sistemas de comunicación mediante mochilas $4 \mathrm{G}$.

En otros programas de la productora Cuarzo como Liarla Pardo, indica Peña (2020) que las señales llegan a control de realización una vez gestionadas por los departamentos de ingeniería y control central. Ese procedimiento de ingesta de señales a través de un proceso intermedio es el que han utilizado en Mediaset, tal como nos describen Jorge Alonso, Jefe de Realización de Informativos y Federico Atienza, Jefe de Producción de Informativos ambos de Mediaset España. (Atienza, F. y Alonso, J., comunicación personal, 26 de mayo de 2020):

Hemos habilitado en Mediaset una sala técnica, creada para la ocasión, donde se han implementado Zoom, Skype, Microsoft Teams, Facetime, Whatsapp. Aquí se ha centralizado -como un mini MCR (Master Control Room)- para dar servicio a todos los programas de Mediaset. Está operada por dos técnicos y se ha configurado por matriz para que llegue a todos los estudios de nuestras instalaciones. De esta manera, realizan las llamadas de todos los colaboradores (propios, externos, invitados) adaptándonos al sistema que tengan en su casa y desde esta sala se transfiere por fibra interna a cualquier programa (ej. Informativos, Ana Rosa, Sálvame, Cuatro al día o Viva la vida). Desde aquí, previamente a pasarlo al control de realización, hacen la conexión, regulan el 
COVID-19: contenidos audiovisuales a partir del uso de herramientas domésticas

audio por si hay que amplificarlo, ajustan el plano y retocan pequeños parámetros. También establecen los distintos envíos de monitorización de audio. (Atienza y Alonso, 2020)

Por su parte, Atienza y Alonso (2020), indican que "las órdenes siempre pasan por este mini control que es quien tiene la interlocución con la persona en videollamada y lo que se traslada es solo el IFB (Interruptible foldback) y comunicación con el estudio oportuno por Intercom".

Si observamos el tipo de realización en función de si es en directo o grabado, Emili Planas; Chief Technical Officer (CTO) de Mediapro (Planas, E., comunicación personal, 29 de mayo de 2020), indica que los procesos tampoco son los mismos teniendo en cuenta un directo que una grabación, algo que señala también Peña (2020) y que confirma Javier Torrijos, Supervisor de Branded Content de TBS, Telefónica Broadcast Services (Torrijos, J, comunicación personal, 20 de mayo de 2020), que han usado Teams de Microsoft, la herramienta de videollamadas que usan en Movistar de forma corporativa. En su caso, dado que están haciendo producto grabado, la preproducción y la postproducción se realiza en remoto, excepto la fase de rodaje que se hace de forma presencial, pero con equipo reducido.

Planas (2020) expone que para la realización de directos se habilitaron sistemas específicos de gestión de vídeo por internet (NDI Network Device Interface) a través de redes privadas virtuales. Uno de los problemas de trabajar de esta forma es la velocidad y calidad de las imágenes, pero para esta ocasión, los resultados obtenidos son aceptables. Cuando las redes utilizadas han sido públicas, se han utilizado determinados protocolos de seguridad para garantizar la privacidad y, como las redes son de menor velocidad de transmisión de datos, se han utilizado archivos de vídeo codificados en H.264 o H.265 para aligerar el flujo de información.

En cuanto a programas en directo, Santamaría (2020) indica que las órdenes a las personas que intervienen desde casa y las señales de retorno necesarias para las comunicaciones se les enviaban mediante segunda línea de teléfono móvil.

La empresa especializada en software y hardware de producción audiovisual Newtek, ofrece un sistema de gestión de videollamadas múltiples. Dispone de un hardware con distintas entradas y salidas que permiten la conexión hasta de cuatro señales, con posibilidad de hacer ajustes técnicos de imagen de sonido como, por ejemplo, ecualización, balance de blancos, retoque de color y envío de monitorización (NewTek TalkShow VS 4000: una solución a tener muy en cuenta en contribuciones desde casa, s.f.).

Aun así, indica Torrijos (2020) que, en ocasiones, por motivos personales los personajes invitados prefieren intervenir mediante videollamada para evitar que las personas vayan a su domicilio. En ese caso, se usa la herramienta de comunicación que disponga el invitado y se graba a pantalla completa usando las herramientas que dispone la propia plataforma. Ese material que ha quedado almacenado en la nube

Revista de Comunicación y Salud, 2020, Vol. 10, no 2, pp. 25-61 
COVID-19: contenidos audiovisuales a partir del uso de herramientas domésticas

pasa posteriormente a postproducción de primer nivel, ya que el montaje definitivo sí se efectuará físicamente en las instalaciones de Movistar+.

En cuanto a programas en directo, como informativos señala Torrijos (2020) que se han usado redes de VPN's (Virtual Private Network, redes privadas virtuales) para usar de forma remota los equipos que se encontraban físicamente en la sede de Movistar+

En el caso de usar realizaciones en remoto virtuales, Torrijos indica que tanto para programas como Late Motiv como para eventos que organiza Telefónica Broadcast Services han usado Vmix, otro sistema de realización virtual que trabaja de forma similar a Livestream, descrito por Vicente Peña.

Movistar, en este caso como operadora de telecomunicaciones junto a RTVE, desarrollaron meses antes de la crisis sanitaria, una prueba de realización remota mediante un sistema de edge computing. El ejercicio consistió en la retransmisión de una ficción sonora con tres cámaras conectadas al sistema edge y que se realizaban de forma remota en Torrespaña (RTVE y Telefónica hacen la primera realización a distancia sin unidad móvil gracias al edge computing, 2019)

En el caso de la plataforma de Telefónica, para resolver el problema de la edición de vídeo, han trabajado con un protocolo diseñado con las empresas Avid y Datos Media encargado a Teradici, compañía experta en soluciones de escritorio remoto y servidores en la nube. El sistema permite conectar hasta 120 estaciones de edición remotas con calidades cercanas al 4K. "Era algo difícilmente imaginable antes de esta crisis internacional y hoy es una realidad", señala Manuela Martínez, jefa de ingeniería y mantenimiento de Movistar+ (en Avid y Datos Media integran junto a Movistar+ el mayor proyecto en España de acceso remoto a ediciones, 2020)

Las comunicaciones además pueden mejorar a medio plazo con la implantación de la tecnología 5G, -se prevé la implantación entre 2020 y 2030 en Europa-, que supone un avance en la banda ancha móvil, con un sistema de comunicaciones altamente fiable y de baja latencia, y una red de comunicaciones masivas entre máquinas (Crusafón, 2018). Todas las comunicaciones mejorarán, consiguiendo velocidades de transmisión de datos que pueden llegar a $20 \mathrm{~Gb}$ por segundo y con un retardo casi nulo de manera que se lograría una conexión casi en tiempo real (Corral, 2020).

\subsection{Realización}

Una vez vistas las comunicaciones y las herramientas y técnicas que se han usado, pasamos a recabar información sobre los procesos del equipo de realización y control.

El papel de realizador juega un rol esencial en estas nuevas circunstancias. Cuando el control de realización está totalmente virtualizado, es él quien lanza directamente las invitaciones para unirse a la videollamada múltiple y tiene el control sobre la participación y la elección de los planos, suplantando el rol de otros perfiles profesionales como el de ayudante técnico mezclador.

Revista de Comunicación y Salud, 2020, Vol. 10, no 2, pp. 25-61 
COVID-19: contenidos audiovisuales a partir del uso de herramientas domésticas

El principal inconveniente son las limitaciones estéticas, ya que el control técnico virtual es muy limitado. No obstante, puede grabar hasta cuatro señales de vídeo, que funcionan de manera síncrona a través de un mismo código de tiempo, lo que permite realización multicámara o multipantalla, y la posibilidad de hacer operaciones habituales de un control de realización como enmarcar las imágenes (catchear) o rotular.

Respecto a la realización de un programa en control físico y presencial, no hay diferencias respecto a la realización tradicional, ya que la videollamada se contempla como cualquier exterior habitual de DSNG o de mochila 4G. (Atienza y Alonso, 2020), algo en lo que coincide también Peña (2020) y Santamaría (2020).

En este sentido el uso de telefonía móvil se plantea como alternativa al envío de equipos ENGs compuestos por cámara y periodista. De tal forma que el periodista hace de cámara con su teléfono y la aplicación de Aviwest permite tener control del envío y del retorno entre el servidor central y cada terminal. Si bien es cierto que obliga a disponer de un equipo técnico de producción diferente, menos costoso.

Este nuevo flujo de trabajo cambia la fisonomía del equipo ENG (trípode, micro de mano inalámbrico para el periodista, iluminación y cámara) para añadir otros requisitos técnicos, como el estabilizador de mano; cable de audio del teléfono; la batería; la óptica del terminal y la antorcha. Estos elementos se recogen en el webinar de Aviwest $^{2}$ acerca de cómo ha afectado el COVID a la producción.

\subsection{Estética y narración}

La narrativa con este tipo de herramientas condiciona el formato por su falta de ritmo, por su calidad y por el tipo de plano que es menos atractivo visualmente, pero, por el contrario, implica mayor naturalidad y muchas veces, entrar en el hogar de los entrevistados, contertulios o invitados, genera un plus de aliciente para el espectador. (Atienza y Alonso, 2020).

Se trata de herramientas que se han implementado por la situación actual que vivimos y que permanecerán un tiempo, aunque en número y volumen radicalmente inferior al actual. Por su parte Santamaría (2020) cree que son un recurso ocasional que puede tener un cierto frescor para programas determinados, pero no sustituyen a la manera de producir tradicional.

El problema es, en opinión de Santamaría (2020), que la calidad de audio y video que generan es bastante baja, aparte del descontrol en iluminación y puesta en escena que llevan consigo. Según los entrevistados, no tienen la factura profesional que se le debe exigir a una emisora. Tampoco esta crisis ha propiciado una innovación de la producción, sino que, por necesidades ajenas al oficio, se han tenido que utilizar unas

2 Webinar Aviwest. How the Coronavirus is affecting the media industry. 30 abril 2020. Jornada con participantes de toda Europa. https://bit.ly/3iVZeBk

Revista de Comunicación y Salud, 2020, Vol. 10, no 2, pp. 25-61 
COVID-19: contenidos audiovisuales a partir del uso de herramientas domésticas

herramientas más ligeras que cuentan con una serie de limitaciones técnicas evidentes. Aparte están las limitaciones estéticas porque ver el techo o la librería de las casas de los entrevistados es puntual y, con el tiempo, los espectadores pierden el interés por la monotonía y la falta de espectacularidad.

La estética también es un dato que, según indica Torrijos (2020), ha evolucionado a lo largo del período de confinamiento. Las posibilidades técnicas se han ido implementando para mejorar cuestiones estéticas y narrativas: se dotó de mejores cámaras, sistemas de lectura auto cue, mayor nivel de flujo de datos; lo que repercute en la fluidez de la señal de televisión. Pero aun así la estética de las videollamadas acaba agotando al espectador. De ahí que en Movistar hayan comenzado a trabajar en plató, aunque aún haya invitados en sus domicilios utilizando videollamadas.

No me gustaría como profesional que se rebaje la estética tanto. Vamos a coger lo bueno de esto. Igual no hace falta mandar un redactor con una DSNG para hacer una entrevista. Quizá una en directo la podemos hacer, pero mejorando, no desde abajo, contrapicada mal iluminada como se hace ahora. pero no me gustaría seguir viendo triples y cuádruples ventanas con gente usando Team. (Torrijos, 2020)

Por otro lado, el realizador Álvaro Santamarina, (Santamarina, A., comunicación personal, 10 de julio de 2020) considera que el uso de posiciones de cámara, la cabeza caliente y otros recursos técnicos, cuyo uso se ha visto modificado e, incluso, eliminado, ha influido en la narrativa de los planos. La necesidad de adaptar las escenografías; que en directo transmiten sensación de espectacularidad; han alterado la sensación de construcción del espacio, evolucionando hacia atmósferas de ensoñación, mediante la iluminación más oscura, íntima y el uso de planos más largos.

El hecho de la falta de necesidad de no haber público en el plató también ha obligado a buscar otros encuadres, tipo de planos, movimientos y menos profundidad de campo. En consecuencia, se ha visto afectado el uso de cámaras, movimientos y planos más largos, la escenografía y la iluminación en la producción de directos.

\subsection{Televisión y teletrabajo}

En cuanto al personal implicado en la realización de programas de televisión, se han visto abocados a permanecer en casa (Así golpea el coronavirus a las cadenas de televisión, 2020). Esta situación ha supuesto una aceleración forzada del teletrabajo que ha servido para ver los pros y contras que implica en cada área.

El teletrabajo ha llegado para quedarse. Aunque es pronto para saberlo, seguimos en fase de experimentación, está siendo un banco de pruebas extraordinario para implementar avances futuros que beneficien tanto a la empresa como al trabajador y permitan mejorar en variables como la conciliación, la productividad o la rentabilidad dentro de la empresa. (Atienza y Alonso, 2020) 
COVID-19: contenidos audiovisuales a partir del uso de herramientas domésticas

También Santamaría (2020) considera que el teletrabajo formará parte de nuestra realidad laboral casi con toda seguridad, por lo que se tendrá que delimitar qué trabajo se hace desde casa y cuál de manera presencial, lo que creará una nueva situación de relación con la empresa, en la que según el realizador "la presencialidad no está obligada en muchos casos y tendrá más oportunidad la conciliación familiar y una orientación más personal del día a día de cada uno.".

En esta línea, el concepto de ENG o reportero para informativos, sí se ha visto afectado durante el confinamiento, tal y como indica José Jiménez de Andalucía Digital Multimedia (Jiménez, J., comunicación personal, 15 de julio de 2020). En cierta medida este proceso de trabajo, la polivalencia de cámara y periodista se puede considerar que ha venido para quedarse en la producción de informativos, lo que se percibe como una amenaza, ya que altera el flujo de trabajo y, por extensión, las condiciones contractuales.

Pero, además, para cámaras y periodistas, este ahorro de costes implica la aparición de otros factores como la mala calidad de audio y vídeo, de la composición, estabilizador, sonido, movimiento, encuadre son algunos factores que se ven mutado según la Asociación de Cámaras de España ${ }^{3}$.

Por su parte Planas (2020), destaca la posibilidad de reinventar los criterios de selección de personal ya que, en gran parte, desaparece la limitación de la ubicación del profesional. En una empresa internacional como Mediapro, se abre la posibilidad de formar mejores equipos técnicos y creativos sin tener que pensar en qué lugar vive cada persona. Señala de forma clara el "talento" como valor intangible importante para poder contar con un integrante de un equipo que no pueda estar de otra forma mediante la producción deslocalizada.

Santamaría (2020) subraya la importancia de poder trabajar desde casa en tiempo real con el material de vídeo y audio dado que se necesitan manejar paquetes de datos muy grandes. Para Peña (2020) y pensando como realizador, esta situación ha condicionado a la técnica, pero además los contenidos. Se van a hacer cosas en plató, pero quizá no todo el mundo esté en plató.

En cuanto al teletrabajo Torrijos (2020) considera que en su sector de la producción se puede trabajar desde casa, pero hay que trabajar en equipo, hacer reuniones presenciales porque son importantes. Para este productor todo depende del formato de producto, ya que no es lo mismo un informativo, un documental o un largometraje.

No obstante, cree que hay que delimitar y regular los períodos de trabajo ya que durante el confinamiento se estaba conectado 24 horas. En esta línea tanto Jiménez (2020), Santamarina (2020), como Pedro Martín, jefe de unidades móviles en TBS

\footnotetext{
${ }^{3}$ Publicación en Linkedin. 1 julio 2020. https://bit.ly/32R29G2
} 
COVID-19: contenidos audiovisuales a partir del uso de herramientas domésticas

(Martín, P., comunicación personal, 5 de julio de 2020), señalan que el teletrabajo se puede considerar para programas diarios y grabados.

Sin embargo, para directos o informativos, el trabajo en remoto es más complicado. Suponen un reto importante en todos los aspectos. En primer lugar, necesitan una inversión de un sistema de almacenamiento en la nube que tenga rapidez y fluidez. Este tipo de programas se mueven bajo una estructura de trabajo colaborativo que demanda tiempos de disponibilidad, acceso, procesado, descarga, subida y modificación de grandes cantidades de datos en un tiempo muy corto.

Por otra parte, se añade la complejidad que supone la coordinación de todos los equipos y la supervisión de los contenidos previa a la emisión.Pero para Corral (2020) todos estos aspectos se verán mejorados con la implantación de las redes 5G que implican un proceso de deslocalización continuo.

\subsection{Implementación de protocolos}

Durante el Estado de Alarma, los problemas se fueron solucionando a medida que iban surgiendo y los profesionales se concentraron en lograr producciones con la mayor calidad final posible. Sin embargo, una vez pasada la situación y basándose en los datos recopilados durante la crisis, los protocolos se están mejorando (Atienza y Alonso, 2020).

Por tanto, nos encontramos, en estos momentos, ante una fase de actuación directa. Con posterioridad, llegará una fase de análisis y valoraciones que finalizará con un borrador sobre mejoras, optimizaciones y procesos, en aras a desarrollar un protocolo de actuación ante situaciones similares. De esta manera, se podrá garantizar una mayor rapidez de actuación, mayor eficacia y, en definitiva, una mejor respuesta a situaciones de crisis.

Los nuevos protocolos estarán más depurados y preparados y, aunque como señala Planas (2020), existen herramientas para cubrir circunstancias muy diversas, en la mayoría de las operaciones nadie había podido imaginar una situación como ésta. A los sistemas de actuación en caso de emergencia, habitualmente conocidos como "disaster recovery", habrá que hacer algunos añadidos para contemplar situaciones similares.

Esta nueva forma de trabajo no aporta la calidad suficiente pero el ahorro de costes es enorme y la infraestructura implementada no se va a deshabilitar, entre otras cosas porque rebrotes, alertas o situaciones de excepción van a seguir latentes y de todo esto aprendemos, depuramos errores y mejoramos procesos. (Atienza y Alonso, 2020)

Planas (2020) no considera que sean procesos que pasen por una universalización, pero sí que pasan a ser herramientas conocidas, lo que facilita que cuando sea necesario puedan volver a ser usadas. Nunca ha habido una única forma de hacer las

Revista de Comunicación y Salud, 2020, Vol. 10, nº 2, pp. 25-61 
COVID-19: contenidos audiovisuales a partir del uso de herramientas domésticas

cosas, sino que lo que tenemos hoy, son todavía más opciones sobre la mesa para escoger.

La capacidad de reacción en caso de nueva emergencia se acortaría a unas horas según Santamaría (2020) en lugar de semanas como ha ocurrido en esta ocasión. Y será una herramienta que se usará cuando se necesite sobre todo para programas, acciones o campañas dirigidas a redes sociales, Youtube, etc.

\subsection{Sostenibilidad}

La sostenibilidad en el periodo COVID se puede señalar como un efecto en la realidad cotidiana de los ciudadanos, y en particular en la actividad de empresas audiovisuales de producción y eventos.

Se trata de un tema capital en la activación económica del este sector y de la economía presente y futura. Acelerada por la situación de emergencia sanitaria, pero cuyo planteamiento basado en ciclos circulares de la economía se viene esbozando desde hace unos años con una agenda sostenible, recomendaciones y directivas de la Comisión Europea, o los 17 Objetivos de Desarrollo Sostenible de las Naciones Unidas

La sostenibilidad es un factor que mide la actividad del audiovisual en términos de cuidado de procesos, flujos de trabajo, materiales, consumos, usos y costumbres en relación con el entorno en el que se hace la producción.

Las cuestiones tecnológicas y de contenido requieren, por demanda social y pura lógica empresarial, que sean "sostenibles" en términos medioambientales, económicos, sociales, etc. Muchas organizaciones tienen ya como prioridad estratégica y de imagen de marca la reducción de su huella de carbono para rebajar el impacto en lo que conocemos como Emergencia Climática (Corral, 2020)

Atienza y Alonso (2020) comentan el impacto que ha supuesto en muchas partidas presupuestarias. Aspectos como las conexiones en directo, los viajes internacionales y coberturas han supuesto mejora medioambiental por la reducción de desplazamientos. Pero, por otro lado, los vehículos de redacción donde sólo podía viajar una persona por coche, la separación de turnos, las bajas por coronavirus, conexiones con colaboradores internacionales o minutos de emisión en Informativos, se han incrementado y ha supuesto un incremento en costes e impacto ambiental.

Por su parte Planas (2020) sostiene que "la producción remota o deslocalizada tiene un impacto en los temas de sostenibilidad". Antes del periodo COVID-19 desde Mediapro se ha liderado la producción remota, y sus cálculos reflejan un ahorro, en los últimos meses, de $4.000 \mathrm{TN}$ de $\mathrm{CO}^{2}$.

Para Peña (2020) la sostenibilidad no depende de productoras, sino que depende de la concienciación social general, del gobierno y de un pacto de Estado que genere 
COVID-19: contenidos audiovisuales a partir del uso de herramientas domésticas

normativa impositiva en todos los gremios sobre este asunto vital. En la productora Cuarzo se están haciendo gestos como la eliminación de vasos de plástico y se intenta aprovechar y reciclar el papel. La cuestión de decorados es una decisión que depende más de las propias cadenas porque son costes en los que se incurren. Pero se les puede dar una segunda vida ya que un panel decorativo (panneau o panó) se puede pulir, repintar y usar en otro programa. Además, propone que las cuestiones de sostenibilidad las debería gestionar en una producción una persona con conocimientos específicos.

Por otro lado, todos estos factores presentes en la vida laboral y que afectan a flujos de trabajo y los resultados, también requieren de una reflexión sobre la propia actividad de producción y explotación de contenidos. José Jiménez (2020) señala que la sostenibilidad no sólo se ha afectado en ahorro de desplazamientos, sino que su impacto en el freno de la actividad es brutal. Y en los procesos de la empresa para construir el producto audiovisual se ha proyectado sobre el ahorro de luz, refrigeración y uso de platós, la bajada de desperdicios en los contenidos, disminución de la basura en las empresas, desplazamientos, un menor desgaste de material y equipos, menos cantidad de dietas del personal, bajada importante de mantenimientos.

En Telefónica por su parte tienen puntos de reciclaje, los edificios son inteligentes para una gestión eficiente de energía, pero a nivel de producción es más complicado señala Torrijos (2020)

Si tienes que llevar un generador es el que hay, con gasolina y ya está. Que vamos hacia ahí, está claro; pero los consumos de electricidad en tv son los que son porque los platós tienen que iluminarse. Aunque se intenta usar menos HMI y cambiarlos por LED, por ejemplo. Pero hay muchísimo por hacer.

Se tiende al uso de set virtuales porque construyes menos y eso implica ahorro de costes en materiales de construcción, diseño, tiempo, montaje y desmontaje.

Pero no todo es positivo. Las redes, el almacenamiento de datos y los servidores en la nube también tienen un consumo energético. Internet consume tres veces más que toda la energía producida globalmente por plantas solares y eólicas (Corral, 2020). De manera que, si reducimos la presencialidad, aumentamos el teletrabajo y el consumo de datos, la sostenibilidad tampoco está garantizada. El consumo mundial de vídeo bajo demanda es responsable del $1 \%$ de la emisión de gases, que es la misma cantidad que el equivalente a las emisiones de todo un año en España. De manera que hay que ahondar en estudios de sostenibilidad, cálculo de huella de carbono y nuevos modelos de producción para definir con exactitud las mejoras que puede suponer el trabajo a distancia sobre el impacto medioambiental.

\subsection{Flujos de trabajo}

Sobre este importante factor de producción, todos los expertos entrevistados coinciden en la necesidad de revisar los siguientes procesos susceptibles de valoración por la transformación digital: 
COVID-19: contenidos audiovisuales a partir del uso de herramientas domésticas

- Ajuste de tiempos a la baja del número de horas de trabajo en labores de edición y posproducción, y en especial consideración en la elección y mezcla de formatos de vídeo.

- Ajuste en la valoración de criterios técnicos broadcast o de calidad que afectan y afectarán no sólo a las normas editoriales de cadenas de televisión y productoras, sino a una adecuación a la demanda de usuarios y anunciantes en distintas plataformas de entretenimiento.

- Ajuste en los presupuestos y el riesgo de una implantación del low cost ante la necesidad de cubrir horas de emisión.

- Ajuste en la valoración y actualización de los sistemas de archivo y los trabajos de creación de programas a partir de los mismos.

- Ajuste posible en los criterios, funciones y puestos de trabajo en una normalidad laboral en el que la cantidad de personas se ha visto mermada y la oferta de contenido cubierta con menos personal. En este sentido, uno de los primeros indicios es la figura del cámara ENG o reportero, sustituido por un periodista con un móvil en el caso de informativos y con enlaces de contribución y directo sin unidad móvil, con una conexión 4G, Wifi o $5 \mathrm{G}$ si la cobertura lo permitía.

- Un ajuste de procesos de trabajo en programas de diario y en los informativos. En este caso con la falta de público en plató, que incluso ha mermado la espectacularidad, la iluminación y el uso de planos nuevos o escasos.

- Ajuste en los flujos de trabajo en las noticias y su edición.

- Ajuste en la realización y uso de controles multiplató y sets.

- Ajuste de flujo de trabajo hacia un control de calidad necesario en continuidad y controles de realización por parte del departamento de ingeniería de cada canal, no sólo en los directos sino en programas de ficción, semanales.

- Ajuste en el uso y valoración de sistemas de contribución en directo en cuanto a la calidad de audio e imagen de estos. Así como una mayor valoración de los sistemas de intercomunicación entre áreas, interconexionadas o externas que dificultan el trabajo en equipo.

- Ajuste en la adopción de la videollamada en directo, adoptando el modelo radiofónico de participación en el programa. La menor calidad supone resolver problemas de envíos de audio y vídeo, retornos y gestión de feed back a cada persona. Además de añadir procesos de preproducción de instrucciones para invitados de programas con la iluminación y el sonido. Es decir, una mayor complejidad.

\section{DISCUSIÓN}

A la vista de los resultados extraídos de las entrevistas y la revisión de los artículos publicados podemos extraer los siguientes datos que resumen el nuevo entorno derivado del confinamiento. En cuanto a las herramientas técnicas y de software utilizadas para las comunicaciones y la realización en se extraen los datos contenidos en la tabla 3. 
COVID-19: contenidos audiovisuales a partir del uso de herramientas domésticas

Tabla 3. Análisis de herramientas de realización y comunicación.

\begin{tabular}{lll}
\hline \multicolumn{1}{c}{$\begin{array}{c}\text { REALIZACIONES } \\
\text { VIRTUALES }\end{array}$} & SISTEMAS DE VIDEOLLAMADAS & ESCRITORIO REMOTO \\
\hline Livestream Studio & Zoom & Microsoft Teams \\
Vmix & Skype & \\
Uso de tecnología & Edge & DMNG App (Aviwest) \\
Computing & Facetime & \\
& Whatsapp & \\
\hline
\end{tabular}

ENVÍO Y RECEPCIÓN DE MONITOREO DE VÍDEO, AUDIO Y CONTROL

\begin{tabular}{ccc}
\hline $\begin{array}{c}\text { REALIZACIONES } \\
\text { VIRTUALES } \\
\text { (Con gestión integral de } \\
\text { señales) }\end{array}$ & $\begin{array}{c}\text { Livestream studio } \\
\text { Vmix }\end{array}$ & \\
\hline & & $\begin{array}{c}\text { Envío y tratamiento sobre } \\
\text { redes públicas bajo } \\
\text { codificaciones H.264 o }\end{array}$ \\
$\begin{array}{c}\text { CONTROL FísICO DE } \\
\text { REALIZACIÓN }\end{array}$ & $\begin{array}{c}\text { Systel. Creación de una sala MCR para } \\
\text { gestionar señales de videollamadas y } \\
\text { recepción y envío de IFB y N-1 }\end{array}$ & $\begin{array}{c}\text { SRT } \\
\text { Protocolo }\end{array}$ \\
& & $\begin{array}{c}\text { Protocolo Sistemas NDI } \\
\text { para control de señales } \\
\text { en redes privadas VPN }\end{array}$ \\
\hline
\end{tabular}

Fuente: Elaboración propia.

Además, vemos que, en controles de realización físicos, las señales llegan como una más de las disponibles, una vez gestionada por el departamento correspondiente.

Para estructurar los datos obtenidos se ha optado por la realización de un análisis tipo DAFO. A partir del uso de una herramienta de diagnóstico medimos la situación de la industria de la televisión en el estado de confinamiento de la población, y así trazar una o varias estrategias futuras.

Los factores internos se refieren a las fortalezas y debilidades. Se trata de la parte más sencilla del estudio: el análisis interno, al ser la que depende del conocimiento de la actividad de la industria de la televisión y depende directamente de nosotros. Pero ha requerido un ejercicio de autocrítica y honestidad de todas y cada una de las aportaciones de los expertos a partir de las entrevistas realizadas.

Las fortalezas se pueden considerar como una ventaja competitiva. Ambos se cuantifican en los siguientes valores de importancia que se corresponden con la valoración de los expertos: 
COVID-19: contenidos audiovisuales a partir del uso de herramientas domésticas

Tabla 4. Valores del DAFO.

\begin{tabular}{cc}
\hline VALOR & MEDIDA \\
\hline 1 & Irrelevante \\
2 & Poco importante \\
3 & Importancia media \\
4 & Muy importante \\
5 & Importancia crucial \\
\hline
\end{tabular}

Fuente: Elaboración propia.

Los factores externos son variables directas e indirectas que afectan a la actividad televisiva. Es decir, en el caso de España los factores políticos con la declaración del Estado de alarma, las ayudas económicas decretadas por el Gobierno a las televisiones ${ }^{4}$, la situación política, económica y social, la competencia con plataformas de suscripción televisiva, y la adaptación técnica derivada.

Estos factores externos se definen en una serie de variables agrupadas en las amenazas entendidas como factores que afectan negativamente al desarrollo del sector. Y las oportunidades entendidas como aspectos positivos que ofrece el entorno.

Y de este modo se añaden valores en el DAFO en la Tabla 4, que expresan y cuantifican las respuestas de los expertos con las variables aportadas, según la importancia y el consenso existente en las respuestas. Se cuantifican desde el valor uno que se considera irrelevante y hasta el cinco como de importancia crucial. De esta forma se establecen valores de importancia media en tres, y se cuantifican las respuestas obtenidas en la matriz DAFO.

En las tablas 5 a la 14 se detallan y ordenan cada uno de los factores internos de autoanálisis y externos, tanto directos como indirectos de las debilidades y amenazas y divididos en cada uno de los ámbitos extraídos de las entrevistas.

En cuanto a cuestiones de realización desglosadas en la tabla 5, las cuestiones de iluminación y calidad objetiva de la imagen tienen un mayor peso como la debilidad más importante que puede acercar la percepción a una televisión de bajo presupuesto. Por el contrario, los tipos de planos adquieren la menor importancia en cuanto a debilidad de la producción.

Centrándonos en las amenazas, el tener un menor número de cámaras potencia la sensación de monotonía, mientras que la falta de experiencia de usuario en el manejo de las herramientas técnicas puede suponer un problema de alto impacto en la producción.

${ }^{4}$ Con fecha 1 de abril del 2020 se aprobaron determinados gastos de cobertura poblacional obligatoria de los servicios de televisión digital terrestre de ámbito nacional (televisiones privadas), derivados de mantener durante un plazo de seis meses determinados porcentajes de cobertura poblacional obligatoria durante el confinamiento de la población en este periodo. Consultado el 4 junio del 2020. https://bit.ly/2FLI3FE

Revista de Comunicación y Salud, 2020, Vol. 10, nº 2, pp. 25-61 
COVID-19: contenidos audiovisuales a partir del uso de herramientas domésticas

Tabla 5. DAFO. Análisis de Debilidades y Amenazas. Ámbito de la realización.

\begin{tabular}{|c|c|c|}
\hline \multicolumn{3}{|c|}{ REALIZACIÓN } \\
\hline VALOR & $\begin{array}{l}\text { DEBILIDADES } \\
\text { Factores que frenan la actividad }\end{array}$ & $\begin{array}{c}\text { AMENAZAS } \\
\text { Factores que afectan negativamente a la } \\
\text { actividad }\end{array}$ \\
\hline \multirow{2}{*}{3} & $\begin{array}{l}\text { Planos y recursos de baja } \\
\text { calidad }\end{array}$ & \\
\hline & Exceso del uso de multipantalla & \\
\hline \multirow{2}{*}{4} & Estabilización de planos crítica & $\begin{array}{c}\text { Falta de experiencia de usuario a la hora de } \\
\text { manejar herramientas de software }\end{array}$ \\
\hline & $\begin{array}{l}\text { Errores en composición de } \\
\text { planos }\end{array}$ & $\begin{array}{c}\text { Herramientas de realización con limitaciones } \\
\text { técnicas y creativas }\end{array}$ \\
\hline 5 & $\begin{array}{l}\text { Baja calidad de iluminación, } \\
\text { conexiones, imagen y sonido }\end{array}$ & Menor número de cámaras \\
\hline
\end{tabular}

Fuente: Elaboración propia.

En lo que se refiere a las cuestiones estéticas y de contenido reflejadas en la tabla 6, el elemento que aporta más debilidad es la producción de bajo presupuesto identificado como una cuestión de menor calidad e interés en el contenido. Se torna también una amenaza externa en tanto en cuanto podría suponer descensos de audiencia y por tanto reducción de ingresos publicitarios.

Tabla 6. DAFO. Análisis de Debilidades y Amenazas. Ámbito de la estética, contenido y creatividad.

\section{ESTÉTICA, CONTENIDO Y CREATIVIDAD}

\begin{tabular}{ccc}
\hline VALOR & $\begin{array}{c}\text { DEBILIDADES } \\
\text { Factores que frenan la actividad }\end{array}$ & $\begin{array}{c}\text { AMENAZAS } \\
\text { Factores que afectan negativamente a la } \\
\text { actividad }\end{array}$ \\
\hline 1 & Falta de ritmo en los contenidos & \\
\hline 2 & & Monotonía. Falta de interés del espectador \\
\hline 3 & Escenografía de baja calidad & Tendencia a no hacer programas en directo \\
\hline & & \\
& Limitaciones estéticas & \\
\hline
\end{tabular}

Revista de Comunicación y Salud, 2020, Vol. 10, no 2, pp. 25-61 
COVID-19: contenidos audiovisuales a partir del uso de herramientas domésticas

\begin{tabular}{|c|c|c|}
\hline & Menos público en plató & \\
\hline 5 & $\begin{array}{c}\text { Contexto de crisis: programas e } \\
\text { ideas baratos }\end{array}$ & $\begin{array}{c}\text { Falta de innovación en contenidos y } \\
\text { producción }\end{array}$ \\
\hline
\end{tabular}

Fuente: Elaboración propia.

El impacto negativo en los recursos humanos reflejado en la tabla 7 viene dado por la eliminación de algunos puestos de trabajo dado que las funciones son asumidas por otras personas, como es el caso de los mezcladores o los cámaras en equipos de informativos. La hiperconexión laboral también se encuentra entre una de las amenazas que los entrevistados perciben como un riesgo medio-alto.

Los presupuestos también se han visto afectados, como se observa en la tabla 7 , en que, mientras se reduce por una parte al prescindir de personal y pago de dietas, aumenta por el pago de conexiones satelitales para poder cubrir toda la información de la pandemia a nivel mundial.

Tabla 7. DAFO. Análisis de Debilidades y Amenazas. Ámbito del trabajo, recursos humanos y presupuestos.

TELETRABAJO. RECURSOS HUMANOS, PRESUPUESTOS

\begin{tabular}{|c|c|c|}
\hline VALOR & $\begin{array}{l}\text { DEBILIDADES } \\
\text { Factores que frenan la actividad }\end{array}$ & $\begin{array}{c}\text { AMENAZAS } \\
\text { Factores que afectan negativamente a la } \\
\text { actividad }\end{array}$ \\
\hline 1 & & $\begin{array}{l}\text { Reducción de personal en perfiles } \\
\text { específicos: realización, plató e informativos }\end{array}$ \\
\hline 2 & & $\begin{array}{c}\text { Más trabajo individual con menos reuniones } \\
\text { de coordinación }\end{array}$ \\
\hline \multirow{3}{*}{3} & $\begin{array}{l}\text { Programa diario, ausencia de } \\
\text { más personas }\end{array}$ & Reducción de personal: guionistas y técnicos \\
\hline & $\begin{array}{c}\text { Programas semanales a } \\
\text { distancia }\end{array}$ & Hiperconexión laboral \\
\hline & $\begin{array}{l}\text { Eliminación de equipos } \\
\text { tradicionales ENG de cámara y } \\
\text { redactor }\end{array}$ & $\begin{array}{l}\text { Menor inversión de equipos y recursos } \\
\text { Aumento de costes satelitales y conexiones } \\
\text { internacionales para dar información }\end{array}$ \\
\hline 4 & & $\begin{array}{l}\text { Reorganización de funciones de puestos de } \\
\text { trabajo } \\
\text { Nuevos flujos de trabajo más individuales y } \\
\text { menos en equipo }\end{array}$ \\
\hline 5 & $\begin{array}{l}\text { Reorganización del trabajo, } \\
\text { flujos y funciones }\end{array}$ & Disminución de presupuesto \\
\hline
\end{tabular}

Fuente: Elaboración propia.

Revista de Comunicación y Salud, 2020, Vol. 10, nº 2, pp. 25-61 
COVID-19: contenidos audiovisuales a partir del uso de herramientas domésticas

En lo que a comunicaciones se refiere, la excesiva dependencia de redes de comunicación puede suponer una amenaza por posibles fallos como se observa en la tabla 8, pero también la seguridad, la falta de innovación o la pericia de los presentadores a la hora de usar las herramientas de software.

El espacio limitado de almacenamiento por su parte puede suponer una amenaza al proyecto.

Tabla 8. DAFO. Análisis de Debilidades y Amenazas. Ámbito de las comunicaciones.

\begin{tabular}{|c|c|c|}
\hline \multicolumn{3}{|c|}{ COMUNICACIONES } \\
\hline VALOR & $\begin{array}{l}\text { DEBILIDADES } \\
\text { Factores que frenan la actividad }\end{array}$ & $\begin{array}{c}\text { AMENAZAS } \\
\text { Factores que afectan negativamente a la } \\
\text { actividad }\end{array}$ \\
\hline 1 & & Seguridad de las redes \\
\hline 2 & & Falta de innovación técnica \\
\hline 3 & $\begin{array}{l}\text { Aumento del consumo de datos } \\
\text { y espacio de almacenamiento } \\
\text { físico y en nube }\end{array}$ & $\begin{array}{l}\text { Falta de información de software de } \\
\text { videoconferencia, profesionales e invitados }\end{array}$ \\
\hline 4 & Ausencia de redes privadas VPN & Fragilidad de las redes de comunicación \\
\hline 5 & & Dependencia de las redes de comunicación \\
\hline
\end{tabular}

Fuente: Elaboración propia.

Por último, en el ámbito de la sostenibilidad, mientras que el confinamiento llevó a una reducción de emisión de gases, ha habido otras circunstancias que han supuesto un aumento como la duplicidad de viajes o el crecimiento en el uso de datos.

Tabla 9. DAFO. Análisis de Fortalezas y Oportunidades. Ámbito de la sostenibilidad.

\begin{tabular}{|c|c|c|}
\hline \multicolumn{3}{|c|}{ SOSTENIBILIDAD } \\
\hline & $\begin{array}{c}\text { INTERNO } \\
\text { Factores de auto análisis }\end{array}$ & $\begin{array}{c}\text { EXTERNO } \\
\text { Factores directos e indirectos }\end{array}$ \\
\hline VALOR & $\begin{array}{c}\text { DEBILIDADES } \\
\text { Factores que frenan la actividad }\end{array}$ & $\begin{array}{c}\text { AMENAZAS } \\
\text { Factores que afectan negativamente a la } \\
\text { actividad }\end{array}$ \\
\hline 2 & $\begin{array}{l}\text { Aumento del consumo de datos } \\
\text { y su consecuente huella de } \\
\text { carbono } \\
\text { Duplicidad de viajes por } \\
\text { protocolo de salud y aumento de } \\
\text { determinados desplazamientos }\end{array}$ & \\
\hline
\end{tabular}

Revista de Comunicación y Salud, 2020, Vol. 10, no 2, pp. 25-61 
COVID-19: contenidos audiovisuales a partir del uso de herramientas domésticas

Aumento de huella de carbono por incremento en conexiones satelitales e internacionales

Fuente: Elaboración propia.

Por otro lado, las tablas 10 a la 14 se refieren a las fortalezas como ventajas competitivas, y oportunidades como aspectos positivos para crecer.

En cuanto a la realización, desarrollada en la tabla 10, las variables más valoradas se refiere a la grabación de múltiples señales, la realización multicámara y abaratamiento de costes de infraestructura como fortalezas o ventajas competitivas, frente a las oportunidad de un control compartido con varios sets de programas 0 platós.

Tabla 10. DAFO. Análisis de Fortalezas y Oportunidades. Ámbito de realización.

\begin{tabular}{ccc}
\hline \multicolumn{2}{c}{ REALIZACIÓN } \\
\hline VALOR & $\begin{array}{c}\text { FORTALEZAS } \\
\text { Ventajas competitivas }\end{array}$ & $\begin{array}{c}\text { OPORTUNIDADES } \\
\text { Aspectos positivos del entorno para crecer }\end{array}$ \\
\hline 3 & $\begin{array}{c}\text { Herramienta de entretenimiento } \\
\text { de la población }\end{array}$ & \\
& $\begin{array}{c}\text { Grabación de múltiples señales } \\
\text { Realización multicámara } \\
\text { Abaratamiento de costes de } \\
\text { infraestructura }\end{array}$ & Control compartido con varios sets de plató o \\
programas
\end{tabular}

Fuente: Elaboración propia.

En cuanto a la estética, contenido y creatividad (tabla 11) el uso o revisión de programas "muertos" o "de nevera", desechados o no emitidos frente al desarrollo de contenidos nuevos en un nuevo contexto con las facilidades de producción.

Tabla 11. DAFO. Análisis de Fortalezas y Oportunidades. Ámbito de la estética, contenido y creatividad.

\begin{tabular}{ccc}
\hline \multicolumn{2}{c}{ ESTÉTICA, CONTENIDO Y CREATIVIDAD } \\
\hline VALOR & $\begin{array}{c}\text { FORTALEZAS } \\
\text { Ventajas competitivas }\end{array}$ & OPORTUNIDADES \\
\hline \multirow{2}{*}{4} & $\begin{array}{c}\text { Grabación de señales } \\
\text { independientes }\end{array}$ & $\begin{array}{c}\text { Inmediatez para conseguir entrevistados, } \\
\text { cobertura de noticias }\end{array}$ \\
& & Aliciente de entrar en casa del invitado
\end{tabular}

Revista de Comunicación y Salud, 2020, Vol. 10, no 2, pp. 25-61 
COVID-19: contenidos audiovisuales a partir del uso de herramientas domésticas

\begin{tabular}{|c|c|c|}
\hline & $\begin{array}{c}\text { Programas informativos, } \\
\text { grabados, de archivo y falso } \\
\text { directo }\end{array}$ & Ahorro de costes \\
\hline & Valor del archivo audiovisual & Mayor naturalidad \\
\hline 5 & $\begin{array}{l}\text { Revisión de programas } \\
\text { "muertos" o "de nevera", } \\
\text { desechados o no emitidos }\end{array}$ & $\begin{array}{c}\text { Desarrollo de nuevos contenidos } \\
\text { Facilidades de producción }\end{array}$ \\
\hline
\end{tabular}

Fuente: Elaboración propia.

Los datos aportados con relación al teletrabajo, los recursos humanos y la creatividad (tabla 12) contrastan la política de costes ajustada y la conciliación laboral y personal con la adquisición de talento y recursos humanos, junto con nuevos perfiles especialistas en redes y transmisiones.

Tabla 12. DAFO. Análisis de Fortalezas y Oportunidades. Ámbito del teletrabajo, recursos humanos y presupuestos.

\begin{tabular}{|c|c|c|}
\hline \multicolumn{3}{|c|}{ TELETRABAJO. RECURSOS HUMANOS, PRESUPUESTOS } \\
\hline VALOR & $\begin{array}{l}\text { FORTALEZAS } \\
\text { Ventajas competitivas }\end{array}$ & $\begin{array}{c}\text { OPORTUNIDADES } \\
\text { Aspectos positivos del entorno para crecer }\end{array}$ \\
\hline 2 & $\begin{array}{c}\text { Reducción de consumos } \\
\text { eléctricos en instalaciones } \\
\text { Reducción de pago de dietas } \\
\begin{array}{c}\text { Reducción de costes de } \\
\text { mantenimiento }\end{array} \\
\end{array}$ & . \\
\hline 3 & Deslocalización del trabajo & $\begin{array}{l}\text { Flujos de trabajo híbridos presenciales- } \\
\text { remotos }\end{array}$ \\
\hline 4 & & $\begin{array}{c}\text { Aumento de la audiencia } \\
\text { Reducción de desplazamientos } \\
\text { Nuevos diseños de espacios y set }\end{array}$ \\
\hline 5 & $\begin{array}{l}\text { Política de costes ajustada } \\
\text { Conciliación de vida laboral y } \\
\text { personal }\end{array}$ & $\begin{array}{l}\text { Adquisición de talento y recursos humanos. } \\
\qquad \text { A nivel mundial } \\
\text { Nuevos perfiles especialistas en redes y } \\
\text { transmisiones }\end{array}$ \\
\hline
\end{tabular}

Fuente: Elaboración propia.

En cuanto a las comunicaciones (tabla 13) destacan el uso de herramientas de contribución y envío fiables: Wetransfer, Filemale, Dropbox, frente a las oportunidades de manejo de archivos de gran tamaño en tiempo real. 
COVID-19: contenidos audiovisuales a partir del uso de herramientas domésticas

Tabla 13. DAFO. Análisis de Fortalezas y Oportunidades. Ámbito de las comunicaciones.

\begin{tabular}{ccc}
\hline \multicolumn{2}{c}{ COMUNICACIONES } \\
\hline VALOR & $\begin{array}{c}\text { FORTALEZAS } \\
\text { Ventajas competitivas }\end{array}$ & $\begin{array}{c}\text { OPORTUNIDADES } \\
\text { Aspectos positivos del entorno para crecer }\end{array}$ \\
\hline 2 & Avance tecnológico \\
\hline 3 & $\begin{array}{c}\text { Progresiva mejora técnica en sistemas para } \\
\text { el uso doméstico con el uso de equipos de } \\
\text { cámara broadcast y sistemas de lectura } \\
\text { prompter o cue }\end{array}$ \\
\hline 5 & $\begin{array}{c}\text { Uso de herramientas de } \\
\text { contribución y envío fiables: } \\
\text { Wetransfer, Filemale, Dropbox }\end{array}$ & $\begin{array}{c}\text { Posibilidad de manejo de archivos de gran } \\
\text { tamaño en tiempo real }\end{array}$ \\
\hline
\end{tabular}

Fuente: Elaboración propia

Y en cuanto a la sostenibilidad lo más valorado se refiere a la importancia de la reducción de emisiones de gases tóxicos frente a las oportunidades que emergen con el uso de set y decorados virtuales.

Tabla 14. DAFO. Análisis de Fortalezas y Oportunidades. Ámbito de la sostenibilidad.

\begin{tabular}{ccc}
\hline \multicolumn{2}{c}{ SOSTENIBILIDAD } \\
\hline VALOR & $\begin{array}{c}\text { FORTALEZAS } \\
\text { Ventajas competitivas }\end{array}$ & Aspectos positivos del entorno para crecer \\
\hline & $\begin{array}{c}\text { Reducción de consumos } \\
\text { eléctricos en instalaciones } \\
\text { (refrigeración, luz) y por tanto } \\
\text { reducción de huella de carbono } \\
\text { Reducción de residuos en las } \\
\text { empresas productoras y de } \\
\text { televisión }\end{array}$ & Segunda vida a decorados. Economía \\
circular
\end{tabular}

Fuente: Elaboración propia.

En cuanto a la estandarización de procesos y establecimiento de protocolos se considera que, al haber sido una situación improvisada, las técnicas y lecciones aprendidas deberán pasar por un filtro de mejora. Tras ello podrían pasar a ser una

Revista de Comunicación y Salud, 2020, Vol. 10, no 2, pp. 25-61 
COVID-19: contenidos audiovisuales a partir del uso de herramientas domésticas

herramienta más para utilizar en determinadas circunstancias. Sin embargo, no se considera que vayan a ser protocolos universalmente estandarizados.

Donde sí se observa que las técnicas aprendidas podrán ser implementadas sería en productos que necesiten ser atendidos con inmediatez: noticias de última hora, entrevistas de personas relevantes,... Se podría mejorar el resultado de estas a través de la rapidez de actuación y la puesta en marcha del sistema remoto.

La información extraída en cuanto a relaciones laborales indica que se ha mejorado en aspectos como la conciliación de la vida personal y familiar, la productividad y rentabilidad de la empresa gracias a la posibilidad de trabajar de manera remota y en tiempo real con materiales de vídeo y audio de alta calidad.

Sin salir del ámbito laboral, en cuanto a la selección de personal, surge la posibilidad de formar mejores equipos técnicos y creativos sin tener que pensar en qué lugar vive cada persona en búsqueda de talento mediante producción deslocalizada.

Pero también se subraya la regulación de alguna forma ante el riesgo de la hiperconexión y el trabajo $24 / 7$ frente a la desconexión digital laboral sobre todo en trabajos más cercanos a la gestión. No obstante, la posibilidad de prescindir de determinados puestos como un técnico mezclador, o un operador de cámara son aspectos negativos que deja esta situación. Periodistas e invitados más autónomos que no necesitan más que sus dispositivos para elaborar un contenido para televisión.

La sostenibilidad es la asignatura pendiente en la industria audiovisual. Mientras que la implementación de medidas de reciclaje y ahorro energético en oficinas está superada, como industria no se plantean acciones que puedan contribuir de forma significativa a una mejora sostenible. Se asume que los procesos audiovisuales generan un gran impacto energético, sobre todo en iluminación, pero es complicado reducir las prácticas habituales en los flujos de trabajo.

Esta situación de frenazo económico y productivo ha supuesto un impacto en las partidas presupuestarias de viajes y conexiones en directo. La adaptación a las medidas de seguridad, por otra parte, ha perjudicado otros aspectos como la obligación de viajar solo una persona por coche o la separación de turnos.

En cuanto al trabajo en remoto también ha tenido su implicación medioambiental. Se cuestiona si la excesiva dependencia de las redes de datos sea tan beneficioso a nivel sostenible como da la impresión. El uso de internet y dispositivos móviles no se percibe directamente por el usuario como un consumo e impacto en huella de carbono.

Por lo tanto, hay que señalar que mientras no exista una regulación precisa, la industria no se adaptará o lo hará de forma parcial. Mientras que en determinados aspectos se observa que hay una clara mejora, como en cuestión de generación de residuos o transporte, en otros hay un impacto mayor como la movilidad casi individual, el establecimiento de medidas de seguridad higiénico sanitarias con el uso de

Revista de Comunicación y Salud, 2020, Vol. 10, no 2, pp. 25-61 
COVID-19: contenidos audiovisuales a partir del uso de herramientas domésticas

mamparas y mascarillas de alto impacto ecológico y el consumo energético en el uso de redes de comunicaciones para enviar altas cantidades de datos necesarias para el trabajo con materiales de vídeo.

De manera que a nivel sostenibilidad no hay datos concluyentes en cuanto a la influencia de la pandemia. Pero sí se extrae una importante reflexión y es que las empresas no implementan protocolos específicos de sostenibilidad en cuanto a los procesos propios de producción, lo que abre posibilidades a estudios sobre los motivos por los que el audiovisual no contempla esta situación.

\section{CONCLUSIONES}

La aparición de la pandemia provocada por el COVID-19 ha generado cambios radicales en la manera de producir y puede que abra nuevas formas de ejecución y creación audiovisual. Para poder hacer emisión de televisión y contenidos televisivos se puede optar por un sistema de herramientas domésticas, poco profesionales y sin cuidar el detalle; o bien implementar técnicas y protocolos broadcast profesionales, costosos y de lenta implementación.

Todas estas nuevas posibilidades deberían ser definidas en protocolos de trabajo consensuados y articulados por la industria, puesto que modifican los flujos de trabajo. Estas prácticas llevadas a cabo durante los meses de confinamiento apuntan a que se generará un sistema de producción mixto entre los sistemas clásicos de producción audiovisual y los flujos de trabajo que posibilitan las nuevas tecnologías de la información.

En general los elementos usados ya existían, aunque se usaban poco al ponerse en cuestión su calidad técnica de imagen, sonido, control y disponibilidad. La prioridad estética ha quedado en segundo plano en época de confinamiento. Los estándares de calidad volverán una vez se usen las herramientas habituales, pero hay algunos elementos que se pueden considerar que pasarán a ser habituales:

- Los flujos de trabajo, funciones, procesos y roles se pueden reconsiderar en un entorno económico que requiere menos recursos.

- Algunos procesos y técnicas de producción permanecerán en la industria atendiendo, principalmente, al tipo de contenido o a la adaptación de nuevas tecnologías como sistemas de videoconferencia, comunicaciones móviles de alta capacidad o mochilas de transmisión.

- La narrativa, iluminación, número y posición de cámaras, así como la escenografía e iluminación, específica de la calidad inherente a la pandemia se emplearán como recurso habitual.

La situación ha abierto nuevas relaciones laborales, conciliación, y de manera destacable, la búsqueda de talento que se tornará independiente a su localización geográfica. También se abren las puertas a acceder a testimonios directos y en tiempo real que, por su relevancia, pueden estar a disposición de la producción en el mismo instante en que se produzcan. El nuevo escenario post-COVID abre vías, por tanto, a

Revista de Comunicación y Salud, 2020, Vol. 10, no 2, pp. 25-61 
COVID-19: contenidos audiovisuales a partir del uso de herramientas domésticas

nuevos formatos televisivos en el que prime la instantaneidad y el tiempo real. Este factor entrará en conflicto o tendrá que integrarse en la propuesta actual de modelo de negocio basado en la calidad de megaformatos cuyo principal factor de éxito es la espectacularidad y las grandes audiencias (Operación Triunfo, Masterchef...).

El desarrollo tecnológico aportar equipos portátiles y de bajo coste que ayuden a implementar producciones de calidad, sin necesidad de grandes despliegues tecnológicos. Tampoco hay que olvidar que los sistemas de realización virtual pueden aportar valor a plataformas como YouTube y sus creadores de contenidos que quieran distribuir sus creaciones a escala global.

En cuestiones de sostenibilidad se ha puesto de manifiesto que el descenso de desplazamientos es beneficioso para el medio ambiente y eso podría quedar reflejado en la industria audiovisual. Sin embargo, existe la duda de si el impacto que supone el teletrabajo y el uso de comunicaciones de datos son tan beneficiosos como aparentan. Pero es más preocupante que las productoras aún no se plantean de forma consciente la aplicación de criterios sostenibles en sus trabajos, lo que indica que ese aspecto queda desatendido y abre un amplio campo de desarrollo técnico y de investigación.

\section{REFERENCIAS}

Abel Núñez, C. (18 de mayo de 2020). El revolucionario 'kit' de doblaje remoto que ha llegado para quedarse. El Español. Recuperado 29 May, 2020, de https://www.elespanol.com/bluper/noticias/revolucionaria-herramienta-doblaje-desdecasa-mediapro

Al Menos 44 Afectados por misterioso brote de Neumonía en el centro de China. (5 de enero de 2020). $A B C$. Recuperado 28 de mayo de 2020, de https://www.abc.es/sociedad/abci-menos-44-afectados-misterioso-brote-neumoniacentro-china-202001050145 noticia.html

Así golpea el coronavirus a las cadenas de televisión. (13 de marzo de 2020). La Vanguardia. Recuperado 28 de mayo de 2020, de https://www.lavanguardia.com/television/20200313/474108662413/coronavirustelevision-covid-19-telecinco-antena-3-tve-cuatro-la-sexta-programas.html

Asociación de Cámaras de España. (2020) Esto es lo que pasa cuando las cadenas se quieren ahorrar el trabajo de un operador de cámara. [Publicación]. Linkedin. Recuperado el 3 de julio de 2020. https://www.linkedin.com/posts/c\%C3\%A1marasespa\%C3\%B1a manolo-garc\%C3\%ADa-espejo-p\%C3\%BAblico-antena-3-activity$\underline{6685911282354294784-\mathrm{C} 2 \mathrm{~J} 0}$ 
COVID-19: contenidos audiovisuales a partir del uso de herramientas domésticas

Avid y Datos Media integran junto a Movistar+ el mayor proyecto en España de acceso remoto a ediciones. (s.f.). Panorama Audiovisual.com. Recuperado 29 de mayo de 2020, de https://www.panoramaaudiovisual.com/2020/05/19/avid-y-datos-mediamovistar-mayor-proyecto-acceso-remoto-ediciones/

Barlovento Comunicación. (2020). Balance del consumo de televisión durante el Estado de Alarma. (Informe). https://bit.ly/360EkgH

Casanova Mascarell, J. (2016). La producción audiovisual móvil. AdComunica. Revista Científica de Estrategias, Tendencias e Innovación en Comunicación, 12, 231-234. doi: $\underline{10.6035 / 2174-0992.2016 .12 .14}$

Casero-Ripollés, A. (2020). Impact of Covid-19 on the media system: Communicative and democratic consequences of news consumption during the outbreak. El profesional de la Información, 29(2). doi: 10.3145/epi.2020.mar.23

Ceballos, M. et al. (2020). Efectos de la crisis de la COVID-19 en la calidad del aire urbano en España. (Informe). Ecologistas en Acción. https://www.ecologistasenaccion.org/140177

Cepeda, D. (16 de mayo de 2020). El coronavirus pone en peligro las metas de reciclaje. Cinco días. Recuperado 21 de septiembre de 2020, de https://cincodias.elpais.com/cincodias/2020/05/15/companias/1589546188 937111.ht $\underline{\mathrm{ml}}$

Clemente Mediavilla, J. (2004). La incorporación de las nuevas tecnologías al audiovisual: una aproximación a la informatización de la gestión de la producción audiovisual. Área Abierta, 9.

Corral, D. (30 de abril de 2020). Periodismo tecnológico o ¿tecnología para el periodismo?.... en tiempos de pandemia. Ol2. Observatorio para la innovación de los informativos en la sociedad digital. Rtve.es. Recuperado 05 de julio, de https://www.rtve.es/rtve/20200430/periodismo-tecnologico-tecnologia-paraperiodismo-tiempos-pandemia/2013145.shtml

Crusafón, C. (2018). La industria audiovisual ante el despliegue del 5G: el caso de la unión europea. Fonseca, Journal of Communication, 17, 11-22. doi: $\underline{10.14201 / f j c 2018171122}$

Custom Consoles estrena una mampara para controles de realización como respuesta al COVID-19. (s.f.) Panorama Audiovisual.com. Recuperado 3 de julio de 2020, de https://www.panoramaaudiovisual.com/2020/07/03/custom-consoles-mampara-covidcontrol-realizacion/

El Terrat (Productora). (2020). Coronavídeos: historias confinadas [Programa de televisión]. Barcelona: El Terrat

Revista de Comunicación y Salud, 2020, Vol. 10, no 2, pp. 25-61 
COVID-19: contenidos audiovisuales a partir del uso de herramientas domésticas

Francés Domènec, M., Gavaldà, J., Llorca, G. y Peris, Á. (2014). La televisión de la crisis ante el abismo digital. Gedisa.

Gómez, L. (2020). El desafío ambiental: enseñanzas a partir de la COVID-19. MEDISAN, 24(4), 728.

Güell, O. (31 de enero de 2020). La OMS declara la alerta internacional ante la imparable expansión del coronavirus de Wuhan. El País. Recuperado 28 de mayo de 2020, https://elpais.com/sociedad/2020/01/30/actualidad/1580399024 626205.html

de

Heredero Díaz, O. y Reyes Sánchez, F. (2016). Los efectos profesionales de la crisis de la televisión pública española: el creador audiovisual low cost y las nuevas tecnologías. AdComunica. Revista Científica de Estrategias, Tendencias e Innovación en Comunicación, 11, 95-118. doi: 10.6035/2174-0992.2016.11.7

Hermes, J. y Hill, A. (2020). Television's undoing of social distancing. European Journal of Cultural Studies. doi: $10.1177 / 1367549420927724$

IABM (2020). Entrevista con Live U. [Vídeo]. Recuperado el 24 de abril de 2020. https://theiabm.org/in-conversation-with-liveu-and-zixi/

IABM. (2020). Coronavirus impact tracker. [Vídeo]. Linkedin. Recuperado el 24 de abril de 2020. https://www.linkedin.com/posts/iabm covid19-hpa-covid19-activity$\underline{6675683097700306944-n S Z y}$

IABM. (30 de abril de 2020). How the Coronavirus is affecting the media industry. [Videoconferencia] https://zoom.us/webinar/register/WN nv0n tYqQzKvnEbVujOKqw?id=57af7506-177fea11-a811-000d3a0ba026

Latini, G. (2020). Intorno alle rappresentazioni della crisi. Pratiche audiovisive partecipative al tempo del covid-19. Documenti Geografici, 1, 453-462. doi: 10.19246/DOCUGEO2281-7549/202001 28

López, M. y Bulmer, E. (2020) Sostenibilidad y COVID-19. La insostenibilidad del modelo actual y su impulso tras la pandemia. Madrid: EAE Business School.

Mediapro Studios (Productora). (2020). El Intermedio [Programa de televisión]. Madrid: La Sexta

Mediapro Studios (Productora). (2020). Zapeando [Programa de televisión]. Madrid: La Sexta 
COVID-19: contenidos audiovisuales a partir del uso de herramientas domésticas

Menéndez-Manjón Cueto, C. (2003). Repercusiones de las autopistas de la información en el entorno radiotelevisivo. [Tesis, Universidad Complutense de Madrid]. https://eprints.ucm.es/3796/

NewTek TalkShow VS 4000: una solución a tener muy en cuenta en contribuciones desde casa. (s.f.). Panorama Audiovisual. Recuperado 25 de mayo de 2020, de https://www.panoramaaudiovisual.com/2020/04/23/newtek-talkshow-vs-4000solucion-contribuciones-desde-casa/

Ong, J. C. y Negra, D. (2020). The Media (Studies) of the Pandemic Moment: Introduction to the 20th Anniversary Issue. Television \& New Media, 21(6), 555-561. doi: $\underline{10.1177 / 1527476420934127}$

Pérez, A. (7 de mayo de 2020). Así entra el coronavirus en las series. El País. Recuperado 29 de mayo de 2020, de https://elpais.com/television/2020-05-06/asientra-el-coronavirus-en-las-series.html

Pérez-Rufí, J. P. (2018). Producción y edición del vídeo de bajo presupuesto: estudio de caso de "Lost Ones" (Joan Thiele) de Giada Bossi. Revista Mediterránea de Comunicación, 9(2), 291-303. doi: 10.14198/MEDCOM2018.9.2.4

Pérez-Rufí, J. P. (coord.) (2020). La comunicación audiovisual durante la crisis sanotaria del coronavirus COVID $19 . \quad$ Eumed. https://www.eumed.net/libros/index.html

Real Decreto-ley 11/2020, de 31 de marzo, por el que se adoptan medidas urgentes complementarias en el ámbito social y económico para hacer frente al COVID-19. Boletín Oficial del Estado, 91/2020, de 1 de abril, 27885-27972.

Realización remota, producción y streaming profesional para productoras. (s. f.). Ovide. Recuperado 25 de mayo de 2020, de https:/www.ovide.com/alquiler/realizacionremotal

RTVE (Productora) y Morena Films (Productora). (2020). Diarios de la cuarentena [Programa de televisión]. Madrid: TVE

RTVE y Telefónica hacen la primera realización a distancia sin unidad móvil gracias al edge computing. (4 de diciembre de 2019). Telefónica.com. Recuperado 29 de mayo de 2020, de https://www.telefonica.com/es/web/sala-de-prensa/-/rtve-y-telefonicahacen-la-primera-realizacion-a-distancia-sin-unidad-movil-gracias-al-edge-computing

Sedeño Valdellós, A. M., Rodríguez López, J. y Roger Acuña, S. (2016). El videoclip postelevisivo actual. Propuesta metodológica y análisis estético. Revista Latina de Comunicación Social, 71, 332-348. doi: 10.4185/RLCS-2016-1098 
COVID-19: contenidos audiovisuales a partir del uso de herramientas domésticas

Segarra Saavedra, J., Tur Viñes, V. y Del Pino Romero, J. (2017). Branded Web-Serie as an Advertising Strategy. The \#EncuentraTuLugar case. Revista Latina de Comunicación Social, 72, 883-896. doi: 10.4185/RLCS-2017-1198en

Siete y Acción (Productora). (2020). El Hormiguero [Programa de televisión]. Madrid: Antena 3

Suciu, G., Stefanescu, S., Beceanu, C. y Ceaparu, M. (2020). WebRTC role in real-time communication and video conferencing. 2020 Global Internet of Things Summit (GloTS). Dublin: IEEE.

Vinader, R., García, A. y Abuín, N. (2010). Contenidos digitales: el móvil como plataforma de distribución contenidos. En Francés, M., Gavaldá, J., Llorca, G. y Peris, Á. (Eds.), La calidad de los contenidos audiovisuales en la multidifusión digital, 172, 165-178.

\section{AUTOR/ES:}

\section{Julio Blas Blas}

Profesor Asociado Departamento de Comunicación Aplicada. Universidad Complutense de Madrid. Licenciado en Comunicación Audiovisual por la UCM, Máster en Formación del Profesorado de Secundaria y FP (especialidad de Procesos y Comunicación Audiovisual) por la URJC y Técnico Superior en Realización de Proyectos Audiovisuales por la Escuela CES. Profesional en activo desde hace más de 25 años en televisión como realizador y editor además es fundador de Echar a Rodar, Asociación para la Sostenibilidad Audiovisual. En la UCM ha sido tutor de Trabajos Fin de Grado en Publicidad y Relaciones Públicas, Realización y Gestión Audiovisual Digital y de Tecnología Audiovisual. En OBS Business School imparte clases de Comunicación Sostenible en el Máster de Responsabilidad Social Corporativa y Liderazgo Sostenible.

Orcid ID: https://orcid.org/0000-0001-7235-296X

\section{Alberto Luis García García}

Profesor Asociado Departamento de Comunicación Aplicada. Universidad Complutense de Madrid. Profesor Contratado Doctor del Departamento de Ciencias de la Comunicación Aplicada de la Facultad de Ciencias de la Información, de la Universidad Complutense de Madrid. Las líneas clave que definen su trayectoria investigadora son la televisión y radio digital, realidad virtual, postproducción, interactividad e industrias culturales. Cuenta con una amplia experiencia profesional en postproducción y realización televisiva. Miembro de la Academia de TV. Tiene un sexenio vivo de investigación. Profesor del Área de Empresa, especializado en Estructura y Empresa de Radio, y profesor del Área de Tecnología de los Medios Audiovisuales, especializado en realización y postproducción. Ambas asignaturas impartidas en el Grado de 
COVID-19: contenidos audiovisuales a partir del uso de herramientas domésticas

Comunicación Audiovisual. Es especialista en entornos digitales y producción audiovisual de contenidos de ficción y no ficción.

Orcid ID: https://orcid.org/0000-0002-6805-6700

Google Scholar: https://scholar.google.es/citations?user=vMeHVQsAAAAJ\&hl=es

ResearchGate: https://www.researchgate.net/profile/Alberto Garcia20

\section{Ignacio José Martín Moraleda}

Profesor Asociado Departamento de Comunicación Aplicada. Universidad Complutense de Madrid. Profesor PDI Departamento de Comunicación Aplicada. Universidad Complutense de Madrid. Doctor Comunicación Audiovisual y Publicidad. Amplia experiencia en realización y producción en radio, televisión, eventos, directos. Ha impartido clases en el Máster Técnico de Radio y Televisión del CES, Máster en Comunicación Audiovisual para la Era Digital UCM. Formador de actualización en Canal Sur, Telemadrid, Mediaset, Onda Cero, etc. Liderazgo técnico en producción y proyectos de radio, TDT, televisiones, platós, servicios de noticias, videoconferencia, streaming y LED en España y varios países. Ha prestado servicios de producción y transmisión Aviwest, Sony, Panasonic, JVC, Newtek. Profesor de edición y postproducción en la UCM con participación en varias producciones. Director de TFGs, TFMs, autor de artículos sobre tecnología, datos, televisión e interactividad.

Orcid ID: https://orcid.org/0000-0001-9885-9187

Google Scholar: https://scholar.google.es/citations?user=8ASZmoAAAAAJ\&hl=en 